\title{
The clinical management of hepatocellular carcinoma worldwide: A concise review and comparison of current guidelines from 2001 to 2017
}

\author{
Peipei Song ${ }^{1, *}$, Yulong Cai ${ }^{2}$, Haowen Tang ${ }^{3}$, Chuan $\mathrm{Li}^{4}$, Jiwei Huang ${ }^{4}$ \\ ' Graduate School of Frontier Sciences, The University of Tokyo, Kashiwa-shi, Chiba, Japan; \\ ${ }^{2}$ Department of Bile Duct Surgery, West China Hospital, Sichuan University, Chengdu, Sichuan, China; \\ ${ }^{3}$ Hospital and Institute of Hepatobiliary Surgery, Chinese PLA General Hospital, Beijing, China; \\ ${ }^{4}$ Department of Liver Surgery, Liver Transplantation Division, West China Hospital, Sichuan University, Chengdu, Sichuan, China.
}

\begin{abstract}
Summary Hepatocellular carcinoma (HCC) is the fifth most common malignancy and the second leading cause of cancer-related mortality worldwide. In this review, we made a review on current guidelines published from January 2001 to June 2017 worldwide with a focus on the clinical management of HCC. The electronic databases MEDLINE, the Chinese SinoMed, and the Japanese CiNii were systematically searched. A total of 18 characteristic guidelines for HCC management were finally included, including 8 guidelines from Asia, 5 from Europe, and 5 from the United States of America (USA). If guidelines were published in multiple versions, the most recent update was included, and surveillance, diagnosis, and treatment were compared. The composition of and recommendations in current guidelines on HCC varied, so these guidelines were regrouped and diagnostic and treatment algorithms were summarized graphically to provide the latest information to clinicians. The diagnostic criteria were grouped into 2 categories of a "Size-based pathway" and a "Non-size-based pathway." The treatment criteria were divided into 4 categories: $i$ ) Criteria based on the Barcelona Clinic Liver Cancer staging system; ii) Criteria based on the modified Union of International Cancer Control staging system; iii) Criteria based on the Child-Pugh class of liver function; and $i v)$ Criteria based on tumor resectability. Findings from comparison of current guidelines might help target and concentrate efforts to improve the clinical management of HCC. However, further studies are needed to improve the management and outcomes of HCC. More straightforward or refined guidelines would help guide doctors to make better decisions in the treatment of $\mathrm{HCC}$ in the future.
\end{abstract}

Keywords: Hepatocellular carcinoma, clinical guideline, surveillance, diagnosis, treatment

\section{Introduction}

Hepatocellular carcinoma (HCC) is the fifth most common malignancy worldwide, with $>500,000$ new cases annually, and it is the second leading cause of cancer-related mortality worldwide (1-4). Over the past 2 decades, various studies have examined the clinical management of HCC (5-8), which has witnessed

\footnotetext{
*Address correspondence to:

Dr. Peipei Song, Graduate School of Frontier Sciences, The University of Tokyo, 5-1-5 Kashiwanoha, Kashiwa-shi, Chibaken 277-8563, Japan.

E-mail: ppsong-tky@umin.ac.jp
}

remarkable improvements in treatment options and the emergence of new treatments involving certain combinations of drugs. However, the overall outcomes of HCC are still far from satisfactory. In accordance with a management model, guidelines are defined as "systematically developed statements to assist practitioner and patient decisions about appropriate healthcare for specific clinical circumstances" (9). If adequate guidelines are devised, they could: $i$ ) serve as a roadmap for clinicians to develop individualized decision-making algorithms; $i$ i) improve the quality of care and patients' outcomes; and iii) support and influence regional or national authorities that allocate resources (7). 
Table 1. Eighteen characteristic guidelines for the clinical management of $\mathrm{HCC}$ worldwide

\begin{tabular}{|c|c|c|c|c|}
\hline Area/Year & Guidelines & Drafted by & Aspects covered & Ref. \\
\hline \multicolumn{5}{|l|}{ Asia } \\
\hline 2009 & AOS Guideline & Asian Oncology Summit 2009 & $\mathrm{D} \& \mathrm{~T}+\mathrm{P}+\mathrm{S}$ & $(11)$ \\
\hline 2009 & Chinese Guideline* & $\begin{array}{l}\text { Chinese Society of Liver Cancer, } \\
\text { Chinese Society of Clinical Oncology, } \\
\text { Chinese Society of Hepatology Liver Cancer Study Group }\end{array}$ & $\mathrm{D} \& \mathrm{~T}+\mathrm{S}$ & $(12)$ \\
\hline 2010 & APASL Guideline & Asian-Pacific Association for the Study of the Liver & $\mathrm{D} \& \mathrm{~T}+\mathrm{E}+\mathrm{P}+\mathrm{S}$ & $(13)$ \\
\hline 2012 & Saudi Guideline & $\begin{array}{l}\text { Saudi Association for the Study of Liver Diseases and Transplantation; } \\
\text { Saudi Oncology Society }\end{array}$ & $\mathrm{D} \& \mathrm{~T}+\mathrm{E}+\mathrm{P}+\mathrm{S}$ & $(14)$ \\
\hline 2013 & J-HCC Guideline & $\begin{array}{l}\text { Group formed to establish "Guidelines for evidence-based clinical practice } \\
\text { for the treatment of liver cancer" }\end{array}$ & $\mathrm{D} \& \mathrm{~T}+\mathrm{E}+\mathrm{P}+\mathrm{S}+\mathrm{F}$ & $(15)$ \\
\hline 2014 & JSH Guideline & Japan Society of Hepatology & $\mathrm{D} \& \mathrm{~T}+\mathrm{S}$ & $(16)$ \\
\hline 2014 & Korean Guideline & Korean Liver Cancer Study Group and National Cancer Center & $\mathrm{D} \& \mathrm{~T}+\mathrm{E}+\mathrm{P}$ & $(17)$ \\
\hline 2014 & INASL Guideline & The Indian National Association for Study of the Liver & $\mathrm{D} \& \mathrm{~T}+\mathrm{E}+\mathrm{P}+\mathrm{S}$ & $(18)$ \\
\hline \multicolumn{5}{|l|}{ Europe } \\
\hline 2003 & BSG Guideline & British Society of Gastroenterology & $\mathrm{D} \& \mathrm{~T}+\mathrm{E}+\mathrm{S}$ & $(19)$ \\
\hline 2004 & BASL Guideline & Belgian Association for the Study of the Liver & $\mathrm{D} \& \mathrm{~T}+\mathrm{E}+\mathrm{P}+\mathrm{S}$ & $(20)$ \\
\hline 2009 & GOIM Guideline & Italian Southern Oncological Group & $\mathrm{D} \& \mathrm{~T}+\mathrm{E}$ & $(21)$ \\
\hline 2012 & EASL Guideline & $\begin{array}{l}\text { European Association for Study of Liver, European Organization for } \\
\text { Research and Treatment of Cancer }\end{array}$ & $\mathrm{D} \& \mathrm{~T}+\mathrm{E}+\mathrm{P}+\mathrm{S}$ & $(22)$ \\
\hline 2012 & ESMO Guideline & European Society for Medical Oncology & $\mathrm{D} \& \mathrm{~T}+\mathrm{E}+\mathrm{P}+\mathrm{S}+\mathrm{F}$ & $(23)$ \\
\hline \multicolumn{5}{|l|}{ American } \\
\hline 2007 & ACS Guideline** & American College of Surgeons & D\&T & $(24)$ \\
\hline 2010 & WGO Guideline & World Gastroenterology Organization & $\mathrm{D} \& \mathrm{~T}+\mathrm{E}+\mathrm{P}+\mathrm{S}$ & $(25)$ \\
\hline 2010 & NCI Guideline & United States National Cancer Institute & $\mathrm{D} \& \mathrm{~T}+\mathrm{E}$ & $(26)$ \\
\hline 2011 & AASLD Guideline & American Association for the Study of Liver Disease & $\mathrm{D} \& \mathrm{~T}+\mathrm{S}$ & $(27)$ \\
\hline 2017 & NCCN Guideline & National Comprehensive Cancer Network & $\mathrm{D} \& \mathrm{~T}+\mathrm{E}+\mathrm{S}$ & $(28)$ \\
\hline
\end{tabular}

*The National Health and Family Planning Commission (NHFPC) of China also issued the Standards for Diagnosis and Treatment of Primary Liver Cancer (2017) on June 26, 2017 (44), which was an updated version of standards that issued on 2011. **A review article published on J Am Coll Surg by the American College of Surgeons. D\&T, diagnosis and treatment; E, epidemiology; P, prevention; S, surveillance; F, follow-up.

Since the year 2001 when the European Association for the Study of the Liver (EASL) issued their HCC guideline (10), at least 20 guidelines have been published or updated thus far, and each has its own advantages. Nonetheless, gaps in knowledge and areas of controversy regarding certain aspects of HCC management are evident and cannot be ignored.

In this review, we made a review on current guidelines published worldwide from 2001 to 2017 with a focus on the clinical management of HCC. Surveillance, diagnosis, and treatment in the characteristic guidelines were compared to provide the latest information to clinicians.

\section{Characteristic guidelines for the clinical management of HCC}

This review involved a systematically search of the electronic databases MEDLINE, the Chinese SinoMed (http://www.sinomed.ac.cn/zh/), and the Japanese CiNii (http://ci.nii.ac.jp/) for applicable results from January 2001 to June 2017. No language restriction was applied to the search strategy. Search terms (medical subject headings or keywords) included: "hepatocellular carcinoma," "guidelines/practice guidelines," "consensus," "liver cancer," and "liver carcinoma."

Inclusion criteria were as follows: $i$ ) credibility, as measured by whether the guidelines were widely cited by subsequent guidelines or other publications regarding the management of $\mathrm{HCC}$ after the original guidelines were published; ii) influence, an indication that the guidelines were created with the support of government or academic/medical societies and that the guidelines attracted nationwide attention with respect to their implementation and the standard care for HCC; and iii) multifaceted, meaning that the guidelines included aspects of the diagnosis and treatment of $\mathrm{HCC}$ at a minimum. If the guidelines were published in multiple versions, the most recent update was analyzed. Furthermore, references listed in guidelines were manually searched for other potential sources. The title and abstract of retrieved studies were evaluated for relevance and compliance. If compliance was not clearly defined by the abstract, the full text was reviewed for further assessment.

In line with the criteria above, 18 guidelines that were published between 2001 and 2017 were identified for analysis, including 8 guidelines from Asia, 5 from Europe, and 5 from the United States of America (USA) (Table 1) (11-28). These 18 characteristic guidelines were examined with a focus on the clinical management of HCC, and surveillance, diagnosis, and treatment in those guidelines were compared.

\section{High-risk population and surveillance of $\mathrm{HCC}$}

Identification of the risk factors for HCC and devising of appropriate methods for surveillance of the high-risk population are crucial to early diagnosis and a better 
outcome. This process is usually divided into 3 parts: $i$ ) determining risk factors, $i$ i) screening the population with risk factors for individuals who need to be monitored, and iii) devising the form of surveillance that yields the most benefit.

The current review found that 14 of the 18 guidelines clearly described risk factors and surveillance. Most of that information was common among the guidelines, but there were discrepancies among guidelines due to regional differences in disease and other variables. $\mathrm{HCC}$ has been proven to be linked to liver disease independently and its major risk factors can be divided into those that are cirrhosis-related and those that are non-cirrhosis-related. The former includes hepatitis $\mathrm{B}$ virus (HBV) or hepatitis $\mathrm{C}$ virus (HCV) infection, alcoholic cirrhosis, genetic causes (hemochromatosis and tyrosinosis), nonalcoholic steatohepatitis, stage IV primary biliary cirrhosis, alpha one antitrypsin deficiency, and other causes of cirrhosis; the latter includes being an HBV carrier with a family history of HCC, being Asian and elderly (males $\geq 40$ years and females $\geq 40$ years), and being an African/North American black infected with hepatitis B $(28,29)$. Among these risk factors, hepatitis B is the leading cause of HCC in Africa and East Asia while hepatitis $\mathrm{C}$ is the leading cause in Europe, Japan, and North America (30,31). As mentioned, cirrhosis caused by various etiologies is the strongest predictor of $\mathrm{HCC}$, with an associated annual incidence of $\mathrm{HCC}$ of $1-6 \%(32,33)$.

HCC surveillance is cost-effective, and especially so for the high-risk population. A combination of ultrasound (US) and measurement of alpha-fetoprotein (AFP) are the most widely used and effective methods of detecting HCC worldwide $(34,35)$. However, several studies indicated that AFP alone are has limited and inconsistent sensitivity and specificity as a screening biomarker, and elevated levels of AFP may be found in $<20 \%$ of patients with early-stage HCC (36-38). AFP has been excluded from surveillance and/or diagnostic criteria in guidelines issued in some Western countries, such as the 2005 and 2011 versions of the American Association for the Study of Liver Diseases (AASLD) Guideline, the EASL Guideline, and the National Comprehensive Cancer Network (NCCN) Guideline (22,27,28,39).

In contrast, some expert panels consider AFP to be a good surveillance marker due to its wide utility in diagnostic settings, where it has been studied extensively (40), and its role in combination with US, which can significantly maximize early detection of HCC (41). Of the 18 guidelines that were reviewed here, 5 recommended US for screening with AFP while 6 suggested US alone. The usefulness of other biomarkers, including the lens culinaris agglutinin-reactive fraction of AFP (AFP-L3) and des-gamma-carboxy prothrombin (DCP), has been studied $(42,43)$. Use of these biomarkers in HCC surveillance is recommended by the J-HCC Guideline and the JSH Guideline $(12,14)$. Use of DCP as a serum biomarker was also mentioned by the Standards for Diagnosis and Treatment of Primary Liver Cancer published by the National Health and Family Planning Commission (NHFPC) of China on June 26, 2017 (44).

The ideal surveillance interval should be evaluated from the perspective of cost-effectiveness by considering the clinical status and available resources. Generally, the surveillance interval is 6 to 12 months for the high-risk population according to the guidelines. A prospective cohort study found that patients with HBV had a better survival with a surveillance interval of 6 months than with 12 months (45). However, other studies have found no significant differences in survival or the rate of HCC detection with intervals of 6 and 12 months $(46,47)$. Of the 18 guidelines that were reviewed here, 8 tended to recommend a surveillance interval of 6 months and 2 recommended an interval of 6 to 12 months.

The definition and description of the high-risk population varied according to the guidelines. According to the J-HCC Guideline and the JSH Guideline, individuals with a high risk of developing HCC who need to be surveilled are classified as the very-high-risk population or the high-risk population. The very-highrisk population includes: $i$ ) individuals with hepatitis B-related liver cirrhosis and $i$ ) individuals with hepatitis C-related liver cirrhosis. The surveillance protocol for those individuals is a US and measurement of tumor markers (AFP/DCP/AFP-L3) every 3-4 months, or dynamic CT/MRI every 6-12 months for patients with cirrhosis or obesity who cannot readily undergo US. The high-risk population includes: $i$ ) individuals with chronic hepatitis $\mathrm{B}, \mathrm{ii}$ ) individuals with chronic hepatitis $\mathrm{C}$, and iii) individuals with liver cirrhosis (causes other than $\mathrm{HBV}$ or HCV). The recommended form of surveillance is a US and measurement of tumor markers every 6 months.

The NCCN Guideline, INASL Guideline, and EASL Guideline classified patients who are at risk of developing HCC into a cirrhosis group and a noncirrhosis group. The INASL Guideline and EASL Guideline also took liver function (Child-Pugh) into consideration for the cirrhosis group. Those 2 guidelines stress that patients on the waiting list for liver transplantation (LT), regardless of their liver function status, should be screened for HCC in order to detect tumor progression (whether it exceeds conventional criteria) and to help define prioritize transplantation. The NCCN Guideline did not recommend surveilling the noncirrhosis group for chronic HCV with advanced fibrosis, but the INASL Guideline and EASL Guideline do recommend surveilling that group. Similarly, the Saudi Guideline suggests surveillance of all cirrhotic patients, but it also stated that there was insufficient evidence to advise surveillance for chronic hepatitis $\mathrm{C}$ without cirrhosis. The WGO Guideline divided the criteria for HCC screening into 3 parts: hepatitis B carriers, cirrhosis not due to hepatitis B, and general patients. General 


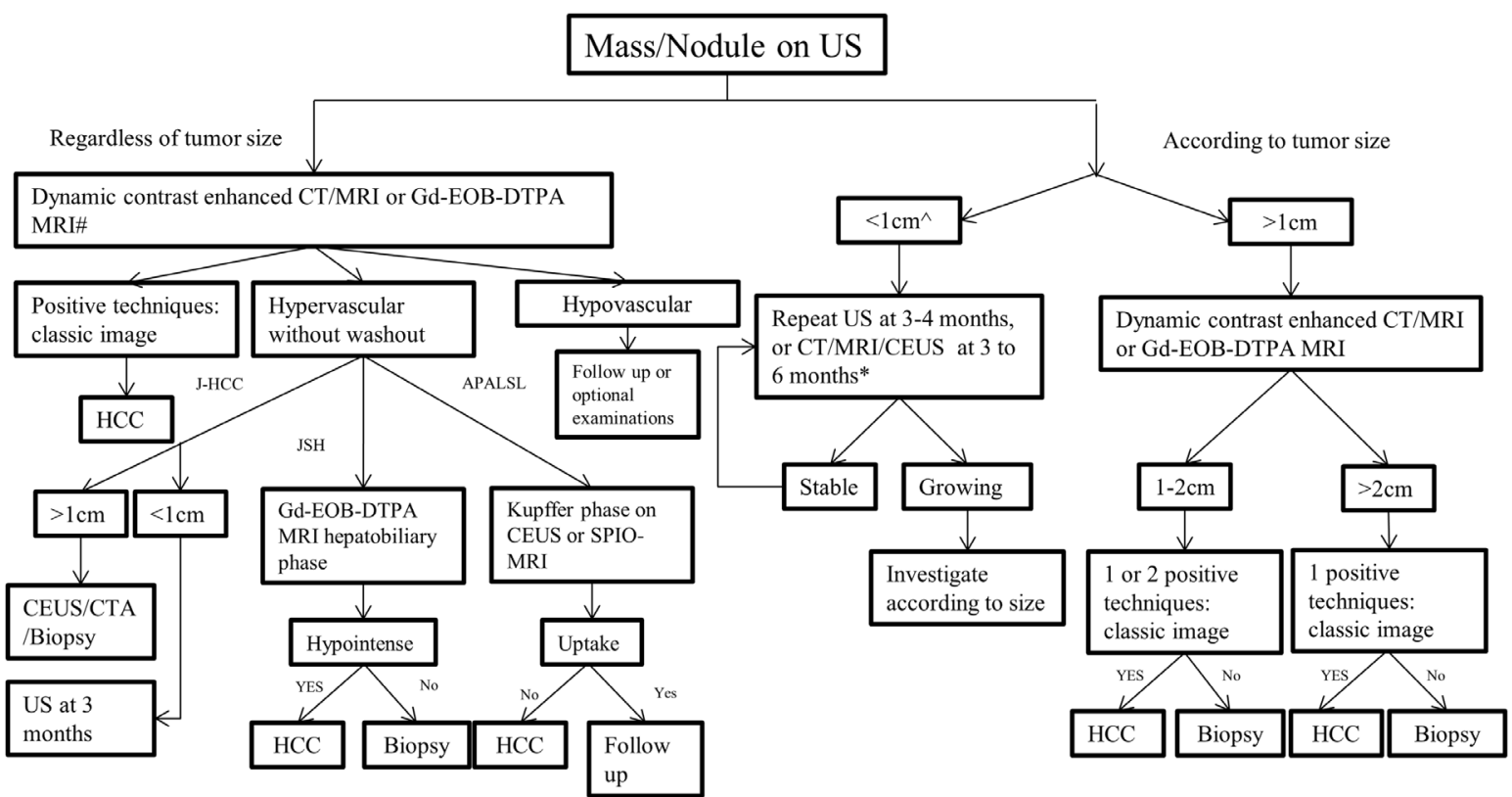

J-HCC/JSH/APASL Guideline

EASL/Korean/AASLD/NCCN/Chinese/Saudi Guideline

Figure 1. The diagnostic algorithm for hepatocellular carcinoma in current guidelines. \# Gd-EOB-DTPA MRI recommended for first-line surveillance and diagnosis of HCC by JSH Guideline. ^ Continuously rising serum AFP level with hepatitis activity under control with two positive techniques of HCC radiological hallmarks can make a diagnosis of HCC by Korean Guideline. * CT/ MRI/CEUS at 3 to 6 months by NCCN Guideline; US at 3-4 months by EASL/AASLD Guideline.

patients referred to patients who were previously eligible for HCC screening and included cirrhotic patients who were successfully treated for chronic viral hepatitis. The AASLD guideline grouped together patients who would benefit from surveillance and patients in whom there was no evidence of a benefit from surveillance. The remaining guidelines did not divide the population who needed to be surveilled into smaller groups.

Obviously, there are regional differences in epidemiology that might change with time. For example, the importance of HBV as a cause of HCC is declining, meanwhile the importance of non-alcoholic fatty liver disease (NAFLD) and nonalcoholic steatohepatitis (NASH) as risk factors for HCC are on a rise (48). Future guidelines should pay close attention to these changes and each country should devise its own method of HCC surveillance depending on local epidemiology. The current comparison of guidelines could help organizations devise a meaningful and easily understood form of surveillance.

\section{Diagnostic criteria for HCC according to characteristic guidelines worldwide}

The diagnosis of HCC is generally based on a combination of clinical and laboratory features, as well as radiographic and histopathologic presentation. The diagnostic algorithms in the 18 guidelines that were reviewed here have been summarized in a flowchart (Figure 1). Although there were differences among the guidelines, the final diagnosis of $\mathrm{HCC}$ was based on imaging techniques or biopsy.

If US reveals a nodule or mass in an at-risk individual, there are mainly 2 pathways for diagnosis of HCC according to current guidelines. These 2 categories were simply designated the "Size-based pathway" and the "Non-size-based pathway."

\subsection{Size-based pathway for HCC diagnosis}

The "Size-based pathway" for diagnosis of HCC starts with tumor size (larger or smaller than $1 \mathrm{~cm}$ ). HCC nodules with a small diameter are difficult to distinguish from cirrhotic nodules, and a previous study found that most nodules with a diameter $<1 \mathrm{~cm}$ were not HCC nodules (49). This is the main reason why the AASLD Guideline and EASL Guideline recommend a close follow-up of those patients by repeating US every 3 or 4 months. The NCCN Guideline recommends at least a contrast-enhanced CT, MRI, or CEUS every 3 to 6 months. Kim et al. argued that hyper-intensity on both T2 and diffusion-weighted images is helpful in the diagnosis of hypervascular HCC nodules smaller than 1 $\mathrm{cm}$ in diameter (50). The Korean Guideline established stricter criteria for diagnosis of HCC nodules $<1 \mathrm{~cm}$. Nodule size according to 2 or more imaging modalities is a typical hallmark of HCC in combination with elevated serum AFP and absence of hepatitis activity (17). The technique that first detected nodules should be performed again 3 to 6 months later. If the nodules have remained 
the same size, a close follow-up should be performed. Otherwise, special attention should be paid to the growing nodule size.

Liver nodules larger than $1 \mathrm{~cm}$ in size should be evaluated with dynamic contrast-enhanced CT/MRI or Gd-EOB-DTPA MRI. Evidence of one or more radiological hallmarks of $\mathrm{HCC}$, arterial hypervascularity, and venous/late-phase washout are considered indicative of HCC. A non-biopsy diagnosis based on a nodule size $>1 \mathrm{~cm}$ has been updated several times. According to the 2002 version of the EASL Guideline, a positive imaging finding plus AFP levels $>400 \mathrm{ng} / \mathrm{mL}$ can result in a diagnosis of HCC when nodules $>2 \mathrm{~cm}$ (22). In 2005, the AASLD Guideline excluded AFP from the diagnostic algorithm and recommended radiological hallmarks according to 2 imaging techniques to diagnose HCC nodules between 1 and $2 \mathrm{~cm}$ in size. For nodules $>$ $2 \mathrm{~cm}$, a hallmark detected by 1 imaging technique would be sufficient (39). The 2010 version of the AASLD Guideline updated criteria as: an imaging technique revealing a radiological hallmark of HCC is sufficient for diagnosis of tumors $1-2 \mathrm{~cm}$ in diameter (19). However, the Chinese Guideline still include AFP $\geq 400$ for 1 month or $\geq 200$ for 2 months as a diagnostic criterion for nodules $1-2 \mathrm{~cm}$ in size (12).

Needle biopsy of a suspicious liver lesion could guide management for patients who do not exhibit a classic imaging presentation and serology, although it is not recommended generally because of the possibility of tumor dissemination outside the liver. The incidence of needle-tract tumor seeding following biopsy of a HCC is $2.7 \%$ overall, or $0.9 \%$ per year $(51)$. Moreover, the NCCN Guideline stresses that a negative biopsy result does not rule out HCC if a nodule or mass has increased in size.

\subsection{Non-size-based pathway for HCC diagnosis}

In the "Non-size-based pathway," patients will be scheduled for dynamic imaging regardless of tumor size. All of the guidelines indicate that a definitive diagnosis of HCC can be made when dynamic CT/MRI reveals intense arterial uptake followed by a "washout" of contrast. Moreover, the updated JSH Guideline includes Gd-EOB-DTPA MRI (gadoxetic acid disodium, a liverspecific contrast agent) as a tool for first-line surveillance and diagnosis of HCC (12). This new contrast agent is specifically absorbed by normal hepatocytes, resulting in contrast enhancement. Therefore, HCC nodules lacking normal hepatocytes are hypo-intense, and this difference can help distinguish tumors from non-tumorous ("normal") nodules $(52,53)$.

When an advanced imaging technique reveals only hypervascularity with no washout, the diagnostic algorithms differ among the guidelines that were reviewed here. Recommendations in the $\mathrm{J}-\mathrm{HCC}$ Guideline (15) depend on tumor size. If the tumor diameter is larger than $1 \mathrm{~cm}$, other optional examinations should be performed, including Gd-EOB-DTPA-MRI, SPIO-MRI, CEUS, CTA, and biopsy. A 3-month followup is recommended for patients with a tumor $<1 \mathrm{~cm}$ in diameter and elevated levels of tumor markers while dynamic CT/MR is recommended for a larger tumor. In the JSH Guideline, a tumor that is hypo-intense during the hepatobiliary phase of GD-EOB-DTPAMRI can be diagnosed as HCC provided that cavernous hemangioma is first ruled out by other modalities (16). A biopsy is necessary if the tumor is iso-intense or hyperintense in the hepatobiliary phase. According to the APASL Guideline, a lesion can be diagnosed as HCC when high SPIO-enhanced MRI signals or a defect in the Kupffer phase of Sonazoid-enhanced US is evident (13). However, the APASL Guideline only recommends a close follow-up instead of a biopsy for patients with intense uptake in SPIO-MRI or CEUS.

There is still a lack of a broad consensus on the most appropriate diagnostic algorithm to use when initial dynamic CT/MRI reveals a hypo-vascular mass in the arterial phase. The updated J-HCC Guideline published in 2013 suggested that an optional examination should be undergone by patients with a tumor larger than $1.5 \mathrm{~cm}$ and it suggested a follow-up of 3 months for those with a tumor smaller than $1.5 \mathrm{~cm}$ (15). The JSH Guideline stresses presentation in the hepatobiliary phase of GDEBO-DTPA-MRI. If hypo-intensity is present, Sonazoid CEUS is recommended; otherwise, follow-up should be continued (16). The APASL Guideline tended to recommend SPIO-enhanced MRI or Sonazoid CEUS for those patients (13). A close follow-up was recommended in the event of a negative imaging finding.

\section{Treatment criteria for HCC according to characteristic guidelines worldwide}

The treatment algorithm for HCC is constantly changing as the criteria for hepatic resection expand, locoregional therapies advance, novel targeted systemic therapies are introduced, techniques for internal and external radiation therapy improve, and the possibility of receiving a transplant increase. However, long-term outcomes of HCC depend on both the medical complexity of HCC (involving multiple confounding factors: tumor heterogeneity, liver function and performance status) as well as the choice of an appropriate treatment, posing a challenge for both patients and clinicians.

An important aim of guidelines is to feature upto-date, specific, quality evidence to help clinicians select the most appropriate treatment. Recently updated guidelines include those by the NCCN (2017), Korea (2014), JSH (2014), INASL (2014), J-HCC (2013), ESMO (2012), EASL (2012), and Saudi Arabia (2012). The treatment algorithms in these 8 updated guidelines and in the 10 other guidelines can be grouped into the following 4 categories: $i$ ) Criteria based on the Barcelona 


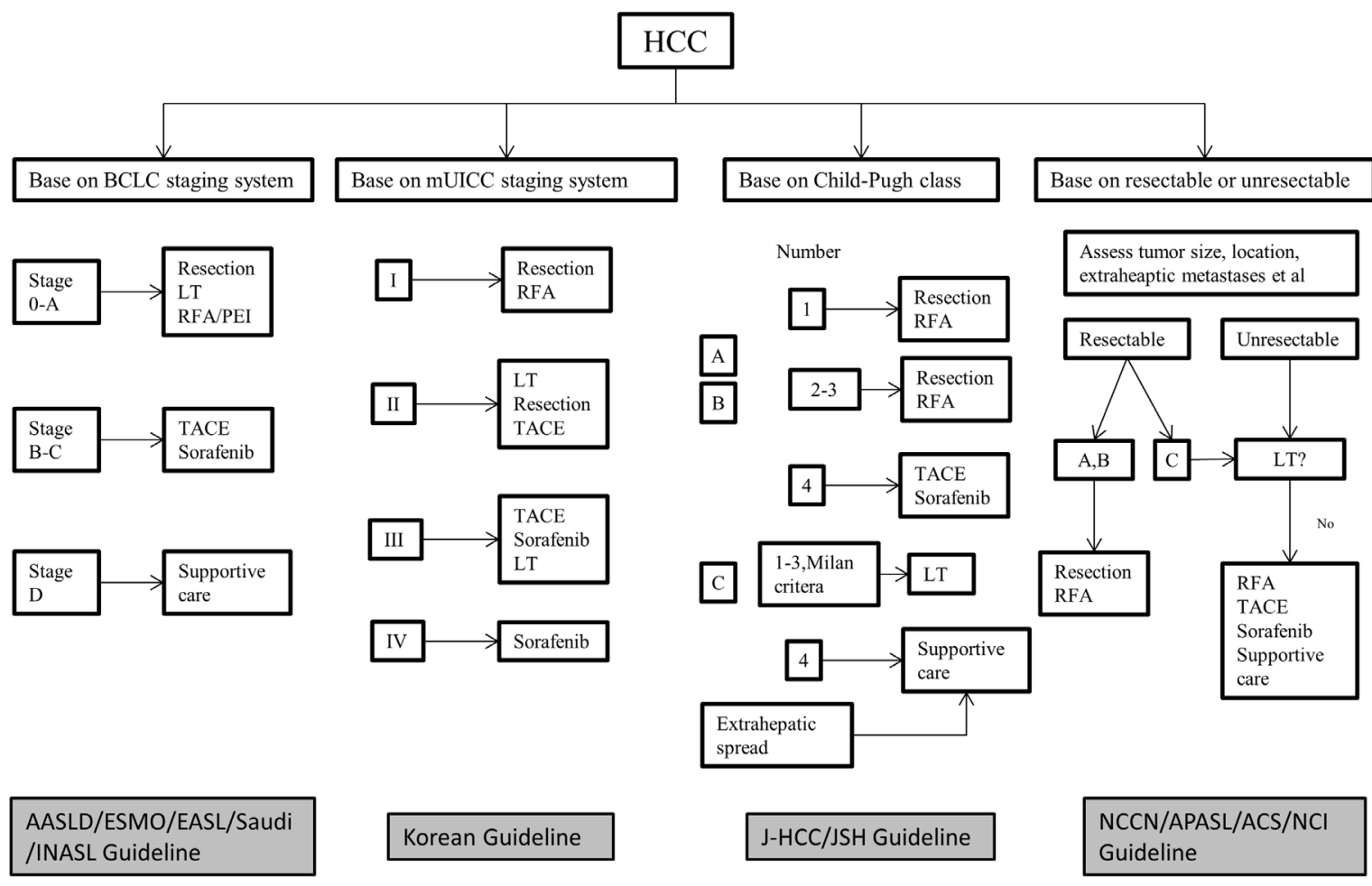

Figure 2. The treatment algorithm for hepatocellular carcinoma in current guidelines. BCLC staging system: Barcelona Clinic Liver Cancer staging system; mUICC staging system: modified Union of International Cancer Control staging system.

Clinic Liver Cancer (BCLC) staging system; ii) Criteria based on the modified Union of International Cancer Control (mUICC) staging system; iii) Criteria based on the Child-Pugh class of liver function; and iv) Criteria based on tumor resectability (resectable or unresectable) (Figure 2).

\subsection{Treatment criteria based on the BCLC staging system}

The BCLC staging system takes tumor stage, liver function, and physical status into account, and this system had been widely adopted for HCC staging and treatment (54). Moreover, the BCLC staging system is the only staging system that assigns treatment strategies based on specific prognostic subclasses, an approach that has proven effective (55). The spectrum of treatment options with curative intent may be a subject of some controversy, but it generally consists of liver resection, LT, and ablation. Patients with stage 0 or stage A liver cancer may have a 5 -year survival rate of $40-70 \%$ after treatment with curative intent. Liver resection still remains the mainstay of $\mathrm{HCC}$ treatment in non-cirrhotic patients or in selected cirrhotic patients with a single lesion. The AASLD Guideline repeatedly stresses the usefulness of measuring portal pressure in predicting patient outcomes and optimizing patient selection for liver resection; this usefulness of this index has also been verified in Japan (56). The AASLD Guideline also indicated that patients with portal hypertension or multiple lesions could receive a survival benefit from resection. The algorithm in the ESMO Guideline excluded hypertension and it expanded the criteria for clinical decision-making with regard to resection (23). The EASL Guideline added a recommendation of anatomical resection, which should be performed wherever feasible particularly for patients with a tumor of 2 to $5 \mathrm{~cm}$ in size (57).

LT is indicated for patients with BCLC stage A cancer meeting the Milan criterion (solitary HCC nodule $<5 \mathrm{~cm}$ in size or fewer than 3 nodules, none larger than $3 \mathrm{~cm}$ in diameter). Patients with cancer meeting the Milan criterion had a 5-year overall survival rate of 65$78 \%$ after LT, which is why this criterion was integrated into the BCLC staging system (58). This strict criterion also has certain limitations. According to the ESMO Guideline, LT is ruled out for patients with cancer meeting the Milan criterion and poor liver function (Child-Pugh class C), who would be classed as BCLC stage D. The University of California San Francisco (UCSF) criterion extends beyond the Milan criterion, and the UCSF criterion results in comparable outcomes according to the INASL Guideline (59). On the whole, primary recommendations for LT have remained the same.

Percutaneous ethanol injection (PEI) and radiofrequency ablation (RFA) are the most widely used forms of ablative treatment. They are considered the standard treatment for HCC that is BCLC 0-A stages and that is not amenable to surgery. Recent studies 
have found that RFA or PEI, as first-line treatment, can yield similar outcomes to surgical resection when tumors are smaller than $2 \mathrm{~cm}$ in size and BCLC stage 0 $(60,61)$. While according to INASL Guideline, patients with stages 0 were only recommended to receive ablation when they were not potential candidates for LT. Substantial evidence is required to verify the effectiveness of ablation as a first-line treatment for very early HCC.

Transarterial chemoembolization (TACE) is the primary treatment option for BCLC stage B HCC (62). The current guidelines reviewed here recommend TACE at about the same level as they did previously. Recent studies have found transarterial radioembolization (TARE) might outperform TACE in terms of tumor downstaging, and its combined use with Yttrium-90 microspheres may result in an encouraging outcome in terms of survival $(63,64)$. Thus, TARE with Yttrium 90 could be considered as an alternative to TACE, particularly is cases of $\mathrm{HCC}$ and portal vein thrombosis.

Molecularly targeted therapy with sorafenib is indicated when BCLC stage C HCC or BCLC stage B HCC progresses after TACE. Two widely cited RCTs have revealed that sorafenib can serve as a first-line treatment in patients with HCC who still have liver function but who can no longer be treated with other more effective therapies $(65,66)$. Recent studies on sorafenib have reported safety data and its efficacy in prolonging survival (67-69).

Patients in the terminal stage (BCLC stage D) should receive the best supportive care. External beam radiation therapy has only been tested in non-controlled studies. The INASL Guideline contends that it cannot recommend radiation therapy for management of HCC until its effectiveness is verified in clinical trials.

\subsection{Criteria based on the mUICC staging system}

The Korean Guideline adopted the mUICC as a primary staging system. Its recommendations for first-line treatment are based on mUICC staging system, but its algorithm only applied to patients with Child-Pugh class A HCC, no portal hypertension, and an Eastern Cooperative Oncology Group (ECOG) performance status of $0-1$. The basic criteria of the mUICC staging system include: $i$ ) the number of tumors, $i i)$ the diameter of the largest tumor, and iii) vascular or bile duct invasion. The best treatment option for a stage I tumor (single/ $\leq 2 \mathrm{~cm} / \mathrm{VI}-$ ) is resection or RFA. There are 3 options for Stage II cancer: $i$ ) resection or RFA (tumor size $\leq 3 \mathrm{~cm}$ ) is recommended for treatment of stage IIa cancer (single/> $2 \mathrm{~cm} / \mathrm{VI}$ ); $\mathrm{ii}$ ) LT (for cancer meeting the Milan criterion) is the first option for treatment of stage IIb cancer (multiple/ $\leq 2 \mathrm{~cm} / \mathrm{VI}-$ ), and TACE or RFA is an alternative when there are more than 3 nodules; and iii) stage IIc cancer (single $/ \leq 2 \mathrm{~cm} / \mathrm{VI}+$ ) is amenable to TACE. The mainstay for treatment of stage III cancer is TACE or sorafenib. However, LT must be taken into account when cancer meets the Milan criterion. Sorafenib is better suited to treatment of a stage IV tumor. The Korean Guideline also added that external beam radiation therapy could be useful in alleviating symptoms caused by primary HCC or metastases.

\subsection{Criteria based on the Child-Pugh class of liver function}

An algorithm based on the Child-Pugh class of liver function is utilized in Japan. The class is based on 3 factors: liver function, the number of tumors, and tumor size. Before a Child-Pugh class is assigned, whether extrahepatic spread is present is first determined. If extrahepatic spread is present, chemotherapy is the treatment of choice for Child-Pugh class A cancer. Palliative care is recommended for patients with decreased liver function. Undoubtedly, liver resection has been the first option for a solitary tumor that is ChildPugh class A/B. According to the 2013 version of J-HCC Guideline (15), RFA is also recommended for tumor $<3$ $\mathrm{cm}$. For patients with 2 to 3 tumor nodules, resection or $\mathrm{RFA} / \mathrm{TACE}$ is recommended depending on their size. For patients with more than 4 tumor nodules, TACE is first recommended, but JSH Guideline contends that resection can sometimes be performed, and ablation is sometimes performed in combination with TACE.

LT is recommended for patients younger than 65 with cancer meeting the Milan criterion, even if they have class $\mathrm{C}$ liver function according to the Child-Pugh score.

\subsection{Criteria based on tumor resectability (resectable or unresectable)}

Treatment algorithms in the NCCN Guideline (2017), APASL Guideline (2010), NCI Guideline (2010), and ACS Guideline (2007) are based on tumor resectability. Initially, tumor resectability should be evaluated based on parameters like liver function, the presence of portal hypertension, tumor location, and the presence of extrahepatic metastases. If a tumor is resectable, resection or RFA (tumor with small diameter) is recommended. LT should also be considered for patients with cancer that is Child-Pugh class C. LT has become the firstline treatment for patients with unresectable tumors that nonetheless meet the Milan or United Network for Organ Sharing (UNOS) criteria. If those patients are not optimal candidates for transplantation, the choice of locoregional therapy, sorafenib, or supportive care depends on individual circumstances (including tumor location, liver function, and institutional capabilities). Moreover, the NCCN Guideline added that transplantation can be considered or recommended for those patients who initially failed to meet the Milan criterion but who received successful downstaging therapy. 


\section{Conclusion}

In this article, we made a review on current 18 characteristic guidelines for HCC management published worldwide between 2001 and 2017, including 8 guidelines from Asia, 5 from Europe, and 5 from the US. This work compared those guidelines in terms of surveillance, diagnosis, and treatment with a focus on the clinical management of HCC. The composition of and recommendations in current guidelines on HCC varied, so these guidelines were regrouped and diagnostic and treatment algorithms were summarized graphically to provide the latest information to clinicians.

Over the past few decades, HCC has changed from an almost universal death sentence to a cancer that can be prevented, detected at an early stage, and effectively treated, but HCC is still the third leading cause of cancerrelated mortality worldwide, and the leading cause of death among patients with chronic liver disease. Findings from this comparison of current guidelines might help target and concentrate efforts to improve the clinical management of HCC. However, further studies are needed to improve the management and outcomes of HCC. More straightforward or refined guidelines would help guide doctors to make better decisions in the treatment of $\mathrm{HCC}$ in the future.

\section{References}

1. El-Serag HB. Hepatocellular carcinoma. N Engl J Med. 2011; 365:1118-1127.

2. Bodzin AS. Hepatocellular carcinoma (HCC) recurrence and what to do when it happens. Hepatobiliary Surg Nutr. 2016; 5:503-505.

3. Forner A, Llovet JM, Bruix J. Hepatocellular carcinoma. Lancet. 2012; 379:1245-1255.

4. Miamen AG, Dong H, Roberts LR. Immunotherapeutic approaches to hepatocellular carcinoma treatment. Liver Cancer. 2012; 1:226-237.

5. Lopez PM, Villanueva A, Llovet JM. Systematic review: Evidence-based management of hepatocellular carcinoma-An updated analysis of randomized controlled trials. Aliment Pharmacol Ther. 2006; 23:1535-1547.

6. Nathan H, Hyder O, Mayo SC, Hirose K, Wolfgang CL, Choti MA, Pawlik TM. Surgical therapy for early hepatocellular carcinoma in the modern era: A 10-year SEER-medicare analysis. Ann Surg. 2013; 258:10221027.

7. Sommacale D, Rhaiem R, Piardi T, Cagniet A, Kianmanesh R. Comments on "Liver resection using total vascular exclusion of the liver preserving the caval flow, in situ hypothermic portal perfusion and temporary porta-caval shunt: A new technique for central tumors". Hepatobiliary Surg Nutr. 2017; 6:207-209.

8. Utsunomiya T, Shimada M, Kudo M, Ichida T, Matsui O, Izumi $\mathrm{N}$, Matsuyama $\mathrm{Y}$, Sakamoto $\mathrm{M}$, Nakashima $\mathrm{O}, \mathrm{Ku}$ Y, Takayama T, Kokudo N; Liver Cancer Study Group of Japan. A comparison of the surgical outcomes among patients with HBV-positive, HCV-positive, and non-B non-C hepatocellular carcinoma: A nationwide study of 11,950 patients. Ann Surg. 2015; 261:513-520.
9. Song P, Tobe RG, Inagaki Y, Kokudo N, Hasegawa K, Sugawara Y, Tang W. The management of hepatocellular carcinoma around the world: A comparison of guidelines from 2001 to 2011. Liver Int. 2012; 32:1053-1063.

10. Bruix J, Sherman M, Llovet JM, Beaugrand M, Lencioni R, Burroughs AK, Christensen E, Pagliaro L, Colombo M, Rodés J; EASL Panel of Experts on HCC. Clinical management of hepatocellular carcinoma. Conclusions of the Barcelona-2000 EASL conference. European Association for the Study of the Liver. J Hepatol. 2001;35:421-430.

11. Poon D, Anderson BO, Chen LT, Tanaka K, Lau WY, Van Cutsem E, Singh H, Chow WC, Ooi LL, Chow P, Khin MW, Koo WH; Asian Oncology Summit. Management of hepatocellular carcinoma in Asia: Consensus statement from the Asian Oncology Summit 2009. Lancet Oncol. 2009; 10:1111-1118.

12. Chinese Anti-Cancer Association Society of Liver Cancer, Chinese Society of Clinical Oncology, Chinese Society of Hepatology Liver Cancer Study Group. The expert consensus on the treatment standards for hepatocellular carcinoma. Digestive Disease and Endoscopy. 2009; 3:4051. (in Chinese)

13. Omata M, Lesmana LA, Tateishi R, et al. Asian Pacific Association for the Study of the Liver consensus recommendations on hepatocellular carcinoma. Hepatol Int. 2010; 4:439-474.

14. Abdo AA, Hassanain M, AlJumah A, et al. Saudi guidelines for the diagnosis and management of hepatocellular carcinoma: Technical review and practice guidelines. Ann Saudi Med. 2012; 32:174-199.

15. Japan Society of Hepatology. Clinical practice guidelines for hepatocellular carcinoma (2013 version). Kanehara, Tokyo, Japan, 2013. (in Japanese)

16. Kudo M, Matsui O, Izumi N, et al. JSH ConsensusBased Clinical Practice Guidelines for the Management of Hepatocellular Carcinoma: 2014 Update by the Liver Cancer Study Group of Japan. Liver Cancer. 2014; 3:458468.

17. Korean Liver Cancer Study Group (KLCSG); National Cancer Center, Korea (NCC). 2014 Korean Liver Cancer Study Group-National Cancer Center Korea practice guideline for the management of hepatocellular carcinoma. Korean J Radiol. 2015; 16:465-522.

18. Kumar A, Acharya SK, Singh SP, et al. The Indian National Association for Study of the Liver (INASL) Consensus on Prevention, Diagnosis and Management of Hepatocellular Carcinoma in India: The Puri Recommendations. J Clin Exp Hepatol. 2014; 4:S3-S26.

19. Ryder SD; British Society of Gastroenterology. Guidelines for the diagnosis and treatment of hepatocellular carcinoma (HCC) in adults. Gut. 2003; 52:iiil-iii8.

20. Van Vlierberghe H, Borbath I, Delwaide J, Henrion J, Michielsen P, Verslype C; BASL HCC working group; BASL steering committee. BASL guidelines for the surveillance, diagnosis and treatment of hepatocellular carcinoma. Acta Gastroenterol Belg. 2004; 67:14-25.

21. Addeo R, Caraglia M, Del Prete S. Highlights of regional meeting of Italian Southern Oncological Group (GOIM): Focus on hepatocellular carcinoma: Biological and clinical background, therapeutic guide-lines and perspectives. 7 November 2008, Naples, Italy. Expert Opin Investig Drugs. 2009; 18:373-378.

22. European Association for Study of Liver; European Organisation for Research and Treatment of Cancer. 
EASL-EORTC clinical practice guidelines: Management of hepatocellular carcinoma. Eur J Cancer. 2012;48:599641.

23. Verslype C, Rosmorduc O, Rougier P; ESMO Guidelines Working Group. Hepatocellular carcinoma: ESMO-ESDO Clinical Practice Guidelines for diagnosis, treatment and follow-up. Ann Oncol. 2012; 23:vii41-vii48.

24. Kim RD, Reed AI, Fujita S, Foley DP, Mekeel KL, Hemming AW. Consensus and controversy in the management of hepatocellular carcinoma. J Am Coll Surg. 2007; 205:108-123.

25. Ferenci P, Fried M, Labrecque D, et al. World Gastroenterology Organisation Guideline. Hepatocellular carcinoma (HCC): A global perspective. J Gastrointestin Liver Dis. 2010; 19:311-317.

26. Thomas MB, Jaffe D, Choti MM, et al. Hepatocellular carcinoma: Consensus recommendations of the National Cancer Institute Clinical Trials Planning Meeting. J Clin Oncol. 2010; 28:3994-4005.

27. Bruix J, Sherman M; American Association for the Study of Liver Diseases. Management of hepatocellular carcinoma: An update. Hepatology. 2011; 53:1020-1022.

28. Benson AB, 3rd, D'Angelica MI, Abbott DE, et al. EASL Guidelines Insights: Hepatobiliary Cancers, Version 1.2017. J Natl Compr Canc Netw. 2017; 15:563-573.

29. Benson AB, 3rd, Abrams TA, Ben-Josef E, et al. NCCN clinical practice guidelines in oncology: Hepatobiliary cancers. J Natl Compr Canc Netw. 2009; 7:350-391.

30. Parkin DM, Bray F, Ferlay J, Pisani P. Global cancer statistics, 2002. CA Cancer J Clin. 2005; 55:74-108.

31. Fattovich G, Stroffolini T, Zagni I, Donato F. Hepatocellular carcinoma in cirrhosis: Incidence and risk factors. Gastroenterology. 2004; 127:S35-S50.

32. Ioannou GN, Splan MF, Weiss NS, McDonald GB, Beretta L, Lee SP. Incidence and predictors of hepatocellular carcinoma in patients with cirrhosis. Clin Gastroenterol Hepatol. 2007; 5:938-45, 945.e1-e4.

33. Sherman M. Hepatocellular carcinoma: Epidemiology, surveillance, and diagnosis. Semin Liver Dis. 2010; 30:316.

34. Zhang BH, Yang BH, Tang ZY. Randomized controlled trial of screening for hepatocellular carcinoma. J Cancer Res Clin Oncol. 2004; 130:417-422.

35. Chang PE, Ong WC, Lui HF, Tan CK. Is the prognosis of young patients with hepatocellular carcinoma poorer than the prognosis of older patients? A comparative analysis of clinical characteristics, prognostic features, and survival outcome. J Gastroenterol. 2008; 43:881-888.

36. Lok AS, Sterling RK, Everhart JE, Wright EC, Hoefs JC, Di Bisceglie AM, Morgan TR, Kim HY, Lee WM, Bonkovsky HL, Dienstag JL; HALT-C Trial Group. Des-gamma-carboxy prothrombin and alpha-fetoprotein as biomarkers for the early detection of hepatocellular carcinoma. Gastroenterology. 2010; 138:493-502.

37. McMahon BJ, Bulkow L, Harpster A, Snowball M, Lanier A, Sacco F, Dunaway E, Williams J. Screening for hepatocellular carcinoma in Alaska natives infected with chronic hepatitis B: A 16-year population-based study. Hepatology. 2000; 32:842-846.

38. Villanueva A, Minguez B, Forner A, Reig M, Llovet JM. Hepatocellular carcinoma: Novel molecular approaches for diagnosis, prognosis, and therapy. Annu Rev Med. 2010; 61:317-328.

39. Bruix J, Sherman M; Practice Guidelines Committee, American Association for the Study of Liver Diseases.
Management of hepatocellular carcinoma. Hepatology. 2005; 42:1208-1236.

40. Tsukuma H, Hiyama T, Tanaka S, et al. Risk factors for hepatocellular carcinoma among patients with chronic liver disease. N Engl J Med. 1993; 328:1797-1801.

41. Marrero JA, Feng Z, Wang Y, et al. Alpha-fetoprotein, des-gamma carboxyprothrombin, and lectin-bound alpha-fetoprotein in early hepatocellular carcinoma. Gastroenterology. 2009; 137:110-118.

42. Huang J, Zeng Y. Current clinical uses of the biomarkers for hepatocellular carcinoma. Drug Discov Ther. 2014; 8:98-99.

43. Song P, Feng X, Inagaki Y, et al. Clinical utility of simultaneous measurement of alpha-fetoprotein and desgamma-carboxy prothrombin for diagnosis of patients with hepatocellular carcinoma in China: A multi-center case-controlled study of 1,153 subjects. Biosci Trends. 2014; 8:266-273.

44. National Health and Family Planning Commission (NHFPC) of China. Standards of Diagnosis and Treatment of Primary Liver Cancer. http://www.nhfpc.gov.cn/yzygj/ s7659/201706/80abf02a86c048fcb130e5e298f7aeee.shtml (Accessed July 10, 2017). (in Chinese)

45. Santi V, Trevisani F, Gramenzi A, et al. Semiannual surveillance is superior to annual surveillance for the detection of early hepatocellular carcinoma and patient survival. J Hepatol. 2010; 53:291-297.

46. Trevisani F, De Notariis S, Rapaccini G, Farinati F, Benvegnù L, Zoli M, Grazi GL, Del PP, Di N, Bernardi M; Italian Liver Cancer Group. Semiannual and annual surveillance of cirrhotic patients for hepatocellular carcinoma: Effects on cancer stage and patient survival (Italian experience). Am J Gastroenterol. 2002; 97:734744.

47. Santagostino E, Colombo M, Rivi M, Rumi MG, Rocino A, Linari S, Mannucci PM; Study Group of the Association of Italian Hemophilia Centers. A 6-month versus a 12-month surveillance for hepatocellular carcinoma in 559 hemophiliacs infected with the hepatitis $\mathrm{C}$ virus. Blood. 2003; 102:78-82.

48. Goh GB, Chang PE, Tan CK. Changing epidemiology of hepatocellular carcinoma in Asia. Best Pract Res Clin Gastroenterol. 2015; 29:919-928.

49. Roskams T. Anatomic pathology of hepatocellular carcinoma: Impact on prognosis and response to therapy. Clin Liver Dis. 2011; 15:245-259, vii-x.

50. Kim JE, Kim SH, Lee SJ, Rhim H. Hypervascular hepatocellular carcinoma $1 \mathrm{~cm}$ or smaller in patients with chronic liver disease: Characterization with gadoxetic acid-enhanced MRI that includes diffusion-weighted imaging. AJR Am J Roentgenol. 2011; 196:W758-W765.

51. Silva MA, Hegab B, Hyde C, Guo B, Buckels JA, Mirza DF. Needle track seeding following biopsy of liver lesions in the diagnosis of hepatocellular cancer: A systematic review and meta-analysis. Gut. 2008; 57:1592-1596.

52. Kudo M. Will Gd-EOB-MRI change the diagnostic algorithm in hepatocellular carcinoma? Oncology. 2010;78:87-93.

53. Lee JM, Yoon JH, Kim KW. Diagnosis of hepatocellular carcinoma: Newer radiological tools. Semin Oncol. 2012; 39:399-409.

54. Richani M, Kolly P, Knoepfli M, Herrmann E, Zweifel M, von Tengg-Kobligk H, Candinas D, Dufour JF. Treatment allocation in hepatocellular carcinoma: Assessment of the BCLC algorithm. Ann Hepatol. 2015; 15:82-90. 
55. Sarma S, Sharma B, Chawla YK, Kapil S, Singla B, Kalra N, Behera A, Duseja A, Dhiman RK. Comparison of 7 staging systems in north Indian cohort of hepatocellular carcinoma. Trop Gastroenterol. 2010; 31:271-278.

56. Ishizawa $\mathrm{T}$, Hasegawa $\mathrm{K}$, Aoki $\mathrm{T}$, Takahashi M, Inoue $\mathrm{Y}$, Sano K, Imamura H, Sugawara Y, Kokudo N, Makuuchi M. Neither multiple tumors nor portal hypertension are surgical contraindications for hepatocellular carcinoma. Gastroenterology. 2008; 134:1908-1916.

57. Dhir M, Melin AA, Douaiher J, Lin C, Zhen WK, Hussain SM, Geschwind JF, Doyle MB, Abou-Alfa GK, Are C. A review and update of treatment options and controversies in the management of hepatocellular carcinoma. Ann Surg. 2016; 263:1112-1125.

58. Llovet JM, Bru C, Bruix J. Prognosis of hepatocellular carcinoma: The BCLC staging classification. Semin Liver Dis. 1999; 19:329-338.

59. Yao FY, Xiao L, Bass NM, Kerlan R, Ascher NL, Roberts JP. Liver transplantation for hepatocellular carcinoma: Validation of the UCSF-expanded criteria based on preoperative imaging. Am J Transplant. 2007; 7:25872596.

60. Livraghi T, Meloni F, Di Stasi M, Rolle E, Solbiati L, Tinelli C, Rossi S. Sustained complete response and complications rates after radiofrequency ablation of very early hepatocellular carcinoma in cirrhosis: Is resection still the treatment of choice? Hepatology. 2008; 47:8289.

61. Peng ZW, Lin XJ, Zhang YJ, Liang HH, Guo RP, Shi M, Chen MS. Radiofrequency ablation versus hepatic resection for the treatment of hepatocellular carcinomas $2 \mathrm{~cm}$ or smaller: A retrospective comparative study. Radiology. 2012; 262:1022-1033.

62. Takayasu K, Arii S, Ikai I, Omata M, Okita K, Ichida T, Matsuyama Y, Nakanuma Y, Kojiro M, Makuuchi M, Yamaoka Y; Liver Cancer Study Group of Japan. Prospective cohort study of transarterial chemoembolization for unresectable hepatocellular carcinoma in 8510 patients. Gastroenterology. 2006; 131:461-469.

63. Lewandowski RJ, Kulik LM, Riaz A, Senthilnathan S, Mulcahy MF, Ryu RK, Ibrahim SM, Sato KT, Baker T, Miller FH, Omary R, Abecassis M, Salem R. A comparative analysis of transarterial downstaging for hepatocellular carcinoma: Chemoembolization versus radioembolization. Am J Transplant. 2009; 9:1920-1928.

64. Salem R, Lewandowski RJ, Mulcahy MF, et al. Radioembolization for hepatocellular carcinoma using Yttrium-90 microspheres: A comprehensive report of long-term outcomes. Gastroenterology. 2010; 138:52-64.

65. Llovet JM, Ricci S, Mazzaferro V, et al. Sorafenib in advanced hepatocellular carcinoma. N Engl J Med. 2008; 359:378-390.

66. Cheng AL, Kang YK, Chen Z, et al. Efficacy and safety of sorafenib in patients in the Asia-Pacific region with advanced hepatocellular carcinoma: A phase III randomised, double-blind, placebo-controlled trial. Lancet Oncol. 2009; 10:25-34.

67. Zhang T, Ding X, Wei D, Cheng P, Su X, Liu H, Wang D, Gao H. Sorafenib improves the survival of patients with advanced hepatocellular carcinoma: A meta-analysis of randomized trials. Anticancer Drugs. 2010; 21:326-332.

68. Terashima T, Yamashita T, Takata N, Nakagawa H, Toyama T, Arai K, Kitamura K, Yamashita T, Sakai Y, Mizukoshi E, Honda M, Kaneko S. Post-progression survival and progression-free survival in patients with advanced hepatocellular carcinoma treated by sorafenib. Hepatol Res. 2015; 46:650-656.

69. Tomuleasa $\mathrm{C}$, Cristea V, Irimie A. Sorafenib for advancedstage hepatocellular carcinoma. Eur J Gastroenterol Hepatol. 2012; 24:346-347.

(Received July 10, 2017; Revised August 22, Accepted August 26, 2017) 